\title{
O experimento de design na educação online: o plano de pesquisa experimental como método.
}

\author{
Pedro Paulo Bezerra Rodrigues"; \\ Raquel Gomes Noronha;
}

resumo:

Este artigo apresenta uma proposta metodológica para compor uma dissertação de mestrado em design voltada para a educação, ensino e aprendizagem, a partir do conceito de plano (program), decorrente dos estudos experimentais em design e design research, visando a utilização de técnicas de experimentação para conduzir uma pesquisa aplicada e qualitativa, buscando o próprio fazer do design como método.

Foi feita uma exposição do plano prévio pesquisa experimental com estudos que tratam da concepção de experimentos de design envolvendo a participação do usuário por meio de artefatos, como as sondas de design, e também da definição de um espaço de experimentação, os laboratórios de design. Esta revisão tem a finalidade de expor este conhecimento agregado acerca do assunto e por fim desenhar um plano de pesquisa viável compreendendo a construção de metodologias.

palavras-chave:

Experimentação; metodologia; pesquisa em design; ensino; aprendizagem.

Espaço reservado para organização do congresso.

\footnotetext{
${ }^{1}$ http://lattes.cnpq.br/2531524941290393

2 http://lattes.cnpq.br/4782161324909358
} 


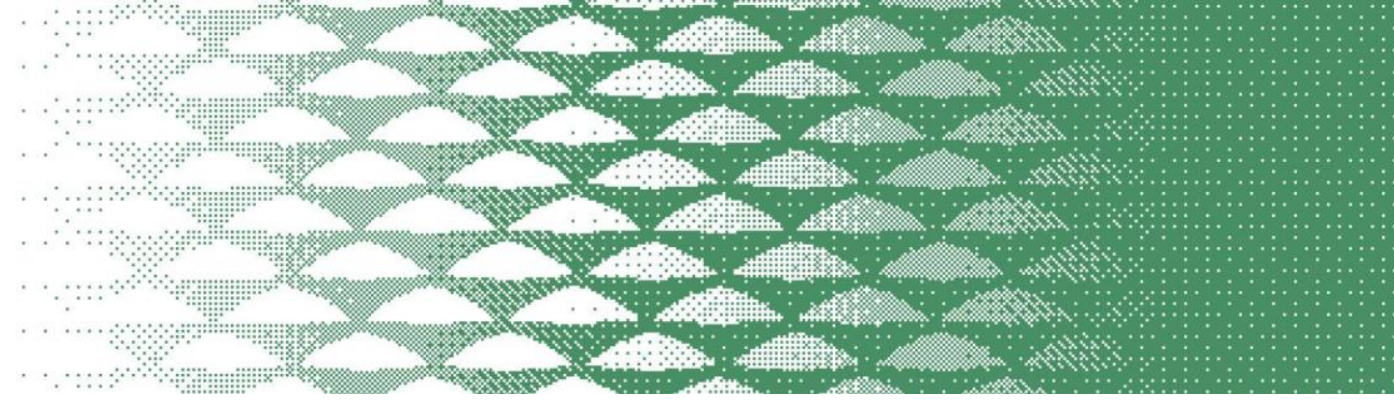

\section{Introdução}

A pesquisa da qual emerge a proposta metodológica aqui apresentada trata-se de uma dissertação de mestrado em andamento, que lida com as problemáticas de uma migração contingencial dos cursos, antes presenciais, para alguma modalidade não presencial, e preferencialmente virtual, devido ao agravamento da pandemia causada pelo Covid-19 (PIMENTEL; CARVALHO, 2020).

Tendo um foco específico no Curso de Design da Universidade Federal do Maranhão, a pesquisa de dissertação visa compreender como a relação docente-discente foi alterada por esta nova realidade; e, por consequência, busca propor novas formas de ensino que possam valorizar as capacidades dos discentes em um momento no qual a educação passou a ser permeada pelas tecnologias digitais.

O ambiente definido para a pesquisa foram as turmas de História do Design I e II, que por concepção são disciplinas com uma abordagem teórica, com pouco envolvimento prático, mas que num contexto remoto adquirem um potencial de mesclar teoria e prática (DEWEY, 1976), conferir autonomia aos discentes (FREIRE, 2010) e propor um ensino mais atencional (INGOLD, 2020).

Portanto, abordando esse problema de forma qualitativa com uma prática de natureza aplicada, o desenvolvimento da pesquisa sugere métodos que gerem engajamento com os sujeitos de pesquisa, com intervenções que perpassem essa mudança de ambiente educacional presencial para virtual.

Dessa forma, neste artigo foi feita uma revisão do plano prévio de ação a ser executado na dissertação, que trouxe à tona a pesquisa experimental em design e que trata de experimentações que buscam envolver a prática de design e a pesquisa em design. Assim, o objetivo deste artigo é apresentar conceitos e práticas que colaborem na sistematização e uso do conceito de experimentos de design como método de pesquisa.

Estas experimentações, que serão tratadas também como experimentos de design, são descritas por Bang e Eriksen (2014) como quaisquer formas de exploração envolvendo mock-ups, protótipos, cenários, modelos, jogos de design, sondas e artefatos. Essas interações consistem em uma ferramenta útil para a geração de conhecimento que localizam o experimento no cerne da pesquisa em design.

Sendo assim, os métodos e técnicas propostos para o desenvolvimento da dissertação são construídos sob a premissa do plano de pesquisa experimental, e é permeado por etapas que compreendem técnicas mais tradicionais da ciência com processos mais voltados à experimentação.

A primeira etapa, de fundamentação teórica estabelecerá uma base de estudos coerentes com a proposta através de revisão sistemática e assistemática de literatura. A etapa de observação compreende a uma observação participante em sala de aula virtual.

A terceira etapa, chamada de sondagem, é a primeira das etapas experimentais, e visa o trabalho com as sondas e prototipagem, nas quais os alunos possam expressar seus desejos e participar no processo de preparação dos conteúdos e avaliações.

A etapa de laboratório trata de uma experimentação em situação real com certo nível de controle, valendo se de atividades planejadas e prototipadas a partir da sondagem. E por fim, a quinta etapa do plano diz respeito à validação, por meio da triangulação de métodos. 


\section{Pesquisa experimental em design}

Apesar de remeter à experimento, esta nomenclatura não deve ser entendida pela denominação clássica das ciências, mas dentro dos preceitos da pesquisa experimental em design (BRANDT; BINDER, 2007). "A noção de experimento evoca imagens de experiências escolares no laboratório de física ou testes quantitativos de parâmetros bem definidos." (BINDER; BRANDT, 2008, p.119, grifo do autor). Brandt e Binder (2007) apontam que vale a pena reivindicar o experimento da ciência e posicioná-lo também na prática dos pesquisadores de design, e complementam:

O que temos em mente não é apenas um ensaio experimental gradativo sobre as qualidades de materiais ou as capacidades de ferramentas ou máquinas. Pensamos no experimento de design [...] como, por um lado, o resultado de um envolvimento integral do design com uma forma possível que pode ser apreciada e avaliada como design e, por outro lado, como uma tentativa deliberada de questionar o que esperamos de tal design. (BRANDT; BINDER, 2007, n.p)

A condução de um experimento de design passa pela compreensão das noções que permeiam essa estrutura de investigação. Binder e Brandt (2007) falam da necessidade de se seguir um planejamento em um processo de pesquisa em design utilizando o termo program, que no contexto desta pesquisa será identificado como plano.

Para Binder e Redström (2006), a pesquisa em design adquire um caráter experimental quando ela é baseada na formulação de um plano de design, que irá estruturar a realização de experimentos e intervenções de design. Binder e Brandt (2007) comentam que o plano aponta um caminho o qual a pesquisa deve seguir, considerando-o como um processo aberto, uma afirmação inicial sujeita a alterações de acordo com o campo.

À medida que a pesquisa avança, o plano também avança definindo o que pode ser explorado de acordo com os contextos iniciais. "[...] o plano é para o pesquisador de design a sugestão que deve ser fundamentada por meio de experimentos." (BINDER; BRANDT, 2007, n.p). O plano de pesquisa em design então pode ser descrito como uma série de procedimentos de cunho prático a serem realizados com o objetivo de responder a questões norteadoras para se compreender processos, interações e anseios dos sujeitos da pesquisa.

Como descrito pelos autores, o plano de pesquisa é uma sugestão provisória do que seguir. Você pode definir as tarefas a serem executadas, mas o desenvolvimento de cada uma delas se dá a partir da finalização de uma tarefa anterior. Cada etapa irá gerar noções importantes para o progresso da pesquisa.

\section{Sondagem}

As sondas fazem parte das formas de exploração por meio de experimentos de design, como já descrito por Bang e Eriksen (2014), e podem ser definidas como um conjunto de atribuições por meio das quais os usuários podem ao mesmo tempo se inspirar e registrar suas experiências, além de expressar seus pensamentos e ideias (MATTELMÄKI, 2006).

As sondas culturais foram desenvolvidas em um projeto de pesquisa comandado por Gaver, Dunne e Pacenti (1999) como forma de provocar reações inspiradoras de idosos e para contribuir com as atuações em suas comunidades locais. "Como as sondas astronômicas ou cirúrgicas, nós as deixamos para trás quando saímos e esperamos que retornassem dados fragmentários ao longo do tempo." (GAVER; DUNNE; PACENTI, 1999, p.22). 


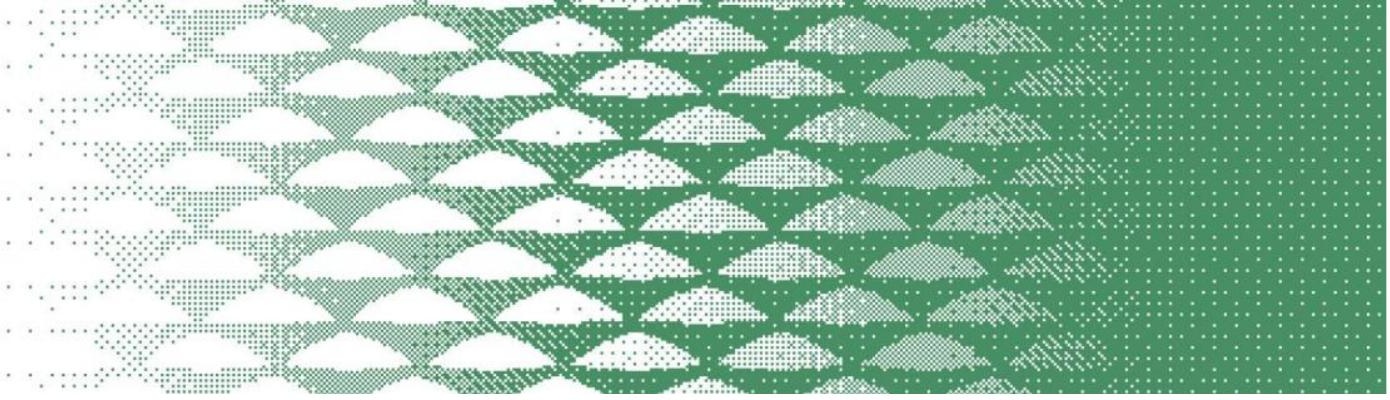

\section{Desenho do método}

O plano de pesquisa em design compreende os métodos e técnicas usados na pesquisa, podendo mesclar etapas mais estabelecidas na pesquisa cientifica com ferramentas experimentais do campo da pesquisa em design.

A sondagem e o laboratório irão compor essa metodologia, mas contam com etapas complementares, como fundamentação teórica e observação, executadas previamente; e validação, que acontecerá após as etapas de experimentação. No Quadro 1 é possível ver o esboço inicial do plano

Quadro 1 - Procedimentos do plano de pesquisa em design

\begin{tabular}{|c|c|c|c|}
\hline Etapas & Objetivo & Técnica & Ambiente \\
\hline $\begin{array}{l}\text { Fundamentação } \\
\text { teórica }\end{array}$ & $\begin{array}{l}\text { Detalhamento do tema } \\
\text { através dos principais } \\
\text { teóricos e estudos similares }\end{array}$ & $\begin{array}{l}\text { Revisão Bibliográfica e } \\
\text { Revisão Sistemática de } \\
\text { Literatura }\end{array}$ & $\begin{array}{l}\text { Livros, artigos, bases de } \\
\text { dados, indexadores e } \\
\text { anais online }\end{array}$ \\
\hline \multirow[t]{2}{*}{ Observação } & $\begin{array}{l}\text { Compreensão das relações } \\
\text { de ensino-aprendizagem em } \\
\text { sala de aula }\end{array}$ & \multirow{2}{*}{$\begin{array}{l}\text { Observação assistemática e } \\
\text { Observação participante }\end{array}$} & \multirow{2}{*}{$\begin{array}{l}\text { Sala de aula virtual: } \\
\text { História do Design I, do } \\
\text { semestre letivo } 2020.2\end{array}$} \\
\hline & $\begin{array}{l}\text { Participação e intervenção } \\
\text { nas dinâmicas de aula }\end{array}$ & & \\
\hline Sondagem & $\begin{array}{l}\text { Desenvolvimento de } \\
\text { protótipos educativos para a } \\
\text { Educação OnLine }\end{array}$ & $\begin{array}{l}\text { Sondas (Probes) e } \\
\text { Princípios da Educação } \\
\text { OnLine (EOL) }\end{array}$ & $\begin{array}{l}\text { Sala de aula virtual: } \\
\text { História do Design II, do } \\
\text { semestre letivo } 2021.1\end{array}$ \\
\hline Laboratório & $\begin{array}{l}\text { Desenvolvimento de } \\
\text { conteúdo programático e } \\
\text { aplicação em aula }\end{array}$ & Experimentações de design & $\begin{array}{l}\text { Sala de aula virtual: } \\
\text { História do Design II, do } \\
\text { semestre letivo } 2021.1\end{array}$ \\
\hline Validação & $\begin{array}{l}\text { Análise dos procedimentos } \\
\text { metodológicos }\end{array}$ & Avaliação por triangulação & - \\
\hline
\end{tabular}

Fonte: Elaborado pelos autores (2021)

A Fundamentação Teórica, pautada pela técnica já amplamente difundida nas ciências da revisão bibliográfica (LAKATOS; MARCONI, 2003; SILVA; MENEZES, 2001) aparece como base, complementada também pela técnica de revisão sistemática de literatura (ULBRICHT et al., 2012). A importância destas revisões está na convergência de conteúdos no arranjo de uma base teórica que possa facilitar o entendimento do problema e fundamentar o seguimento da pesquisa. Para a etapa seguinte, a fundamentação teórica pode definir pontos de interesse que venham a ser correlacionados durante a presença na sala de aula virtual.

A etapa de Observação acontecerá em dois momentos dentro da disciplina de História do Design I. No primeiro, será executada uma Observação Assistemática, que segundo Ander-Egg (1979), “[...] consiste em reconhecer e registrar os fatos sem recorrer ao auxílio de meios técnicos especiais." (ANDER-EGG, 1979, p.88). 


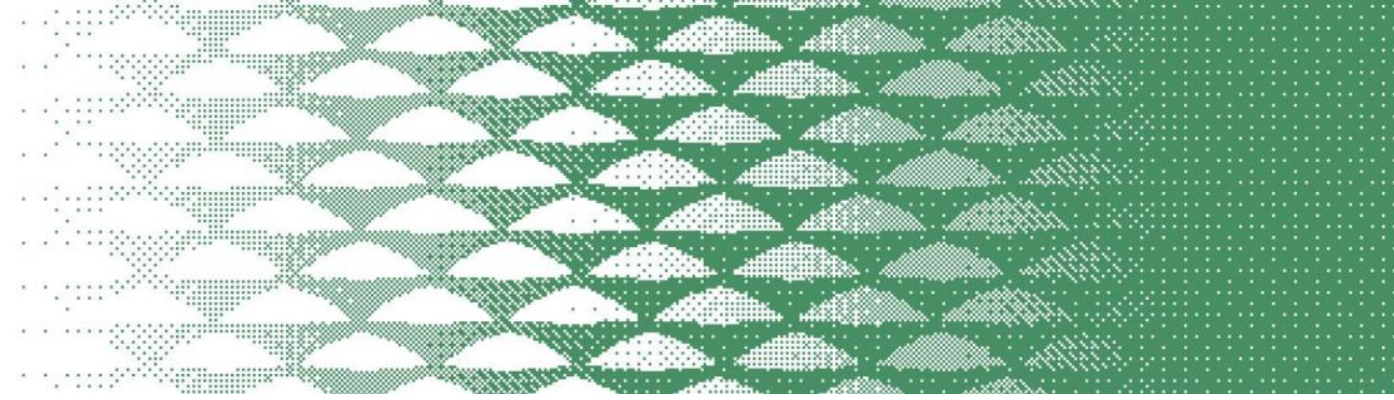

Neste primeiro momento, a observação tem a finalidade de descrever os processos educacionais em uma situação real de ensino-aprendizagem dentro do Curso de Design da UFMA e de que forma que o ensino remoto alterou o cotidiano de estudantes.

Um dos fatores para a escolha desta disciplina é a tendência a estudos mais teóricos, com avaliações que testam a capacidade do aluno de memorizar datas e acontecimentos históricos. Por ser posicionada no primeiro semestre, a turma conta com alunos recém chegados ao ensino superior, em grande parte acostumados a um ensino mais pautado pelo tradicionalismo e hierarquizado.

A disciplina apresenta uma possibilidade de visualizar conceitos que fogem ao tradicionalismo na educação, evocando a interdisciplinaridade e a capacidade de mesclar conhecimentos adquiridos em outras disciplinas do semestre letivo.

No segundo momento, a disciplina de História do Design I será apreciada pela técnica de Observação Participante com a finalidade de imergir mais a fundo nas relações deste ambiente educacional. Para Ingold (2020), "[...] no registro da existência, da vida comum, não pode haver observação sem participação" (INGOLD, 2020, p.89). Na observação participante o pesquisador pratica uma imersão nas "[...] atividades regulares na comunidade, estabelecendo relações de afinidade e tendo acesso aos mecanismos de comunicação do grupo social.” (SANTOS, 2018, p.110-111).

Portanto, a participação se dará por meio de interações com os discentes, escutando suas vozes e seus anseios; também por uma cooperação no planejamento das aulas junto com o professor; já a presença durante as apresentações de trabalho será de suma importância e a posterior colaboração nas avaliações trará noções importantes para o andamento da pesquisa.

$\mathrm{Na}$ Sondagem serão seguidos os conceitos de Mattelmäki (2006) para o desenvolvimento e avaliação das sondas. A Sondagem acontecerá com a mesma turma que participou da Observação, porém será efetuada na disciplina de História do Design II, matéria do segundo semestre da grade do Curso de Design da UFMA, acompanhado assim o andamento do processo de ensino e aprendizagem proposto pelo currículo.

A motivação para a criação do kit de sonda é envolver o corpo discente no planejamento do conteúdo programático. Se a construção das aulas passar pelas mãos de aprendizes, as suas participações podem ser mais efetivas e amplificadas.

Para auxiliar na criação dos kits de sondas, serão empregados os Princípios da Educação Online, elencados por Pimentel e Carvalho (2020). Estes princípios abrangem informações relevantes acerca da passagem massiva da educação presencial para o ambiente virtual, perpassando por preparação de conteúdos, ferramentas e softwares de videoconferência, aprendizagem colaborativa e mediação docente.

O Laboratório consiste em uma etapa de experimentação e visa condensar as informações adquiridas na etapa de Sondagem. Após o retorno e interpretação das sondas, será desenvolvido um conteúdo programático que valorize as ideias apresentadas pelos alunos. Este conteúdo será posto à prova em sala de aula (ação situada) sob as regras do laboratório de design (BINDER; BRANDT, 2008).

Ainda não é possível definir por qual caminho a experimentação caminhará. A conclusão das etapas anteriores é imprescindível para iluminar o trajeto. A criação das sondas passa pela Observação, e o desenvolvimento do conteúdo programático passa pela interpretação e ideação das sondas devolvidas. O plano de design estabelecido é o que vai guiar todo o processo. Ao final das práticas 


\section{JOP 21 DESIGN

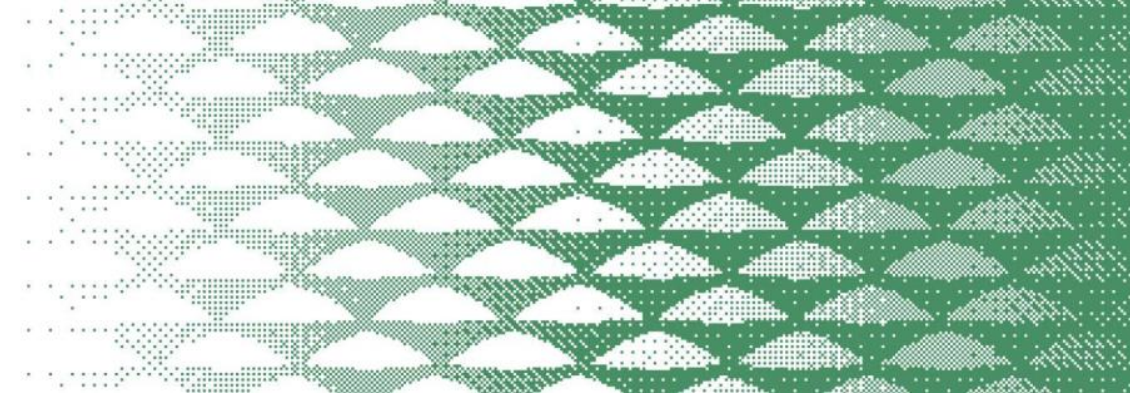

propostas no laboratório de design, a própria etapa de experimentação compreende uma análise de tudo o que foi executado.

No andamento das etapas do plano de pesquisa, são percebidos ciclos de abertura e fechamento. Nos ciclos de abertura a pesquisa se estende para o campo em momentos de interação. Nos ciclos de fechamento essa extensão se recolhe em momentos de reflexão e análise. Essa estrutura sugere uma auto regulação, que pode ser vista na Figura 1.

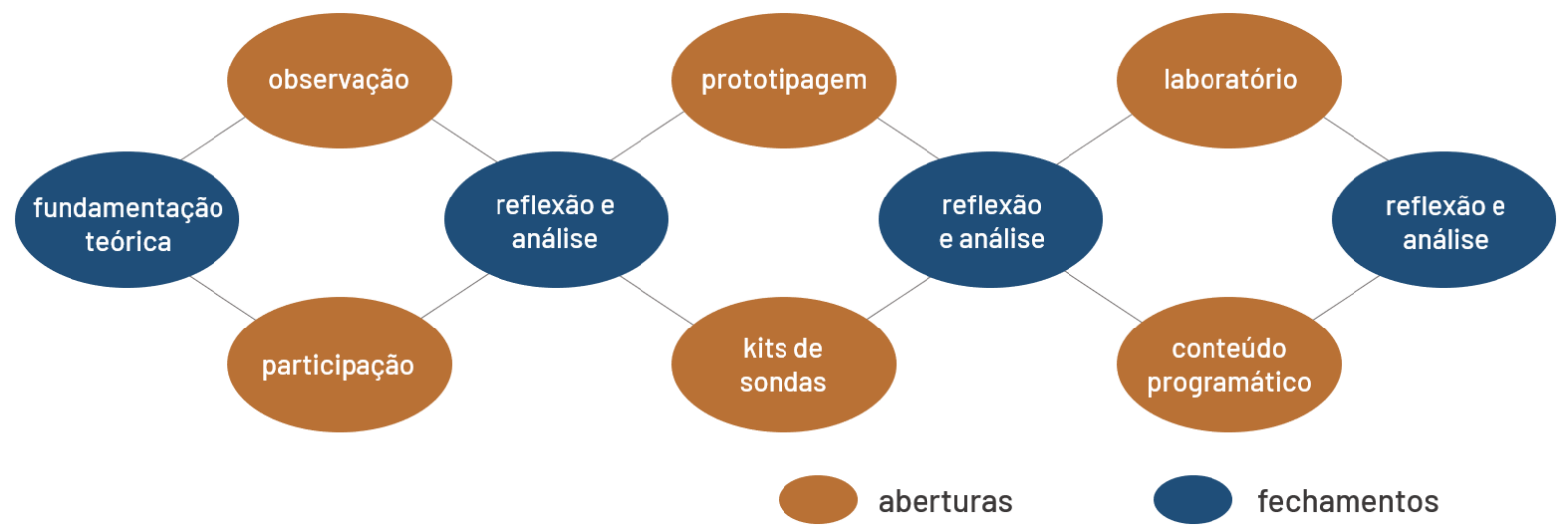

Figura 1 - Aberturas e fechamentos dos processos do plano de pesquisa em design.

Fonte: Elaborado pelos autores (2021)

Ao final de cada etapa, em cada ciclo de fechamento, esse momento de reflexão dará oportunidade de ponderar o que foi percebido e aprendido. Cada ciclo de fechamento também estimula a preparação para a o ciclo de abertura seguinte, num processo de investigação que cresce ao longo da pesquisa.

A etapa de Validação ao final tem o objetivo de trazer confiabilidade, respaldando o que foi colhido durante a execução dos processos. Ela consiste em um último ciclo de retratação que engloba todo o conjunto, como visto na Figura 2.

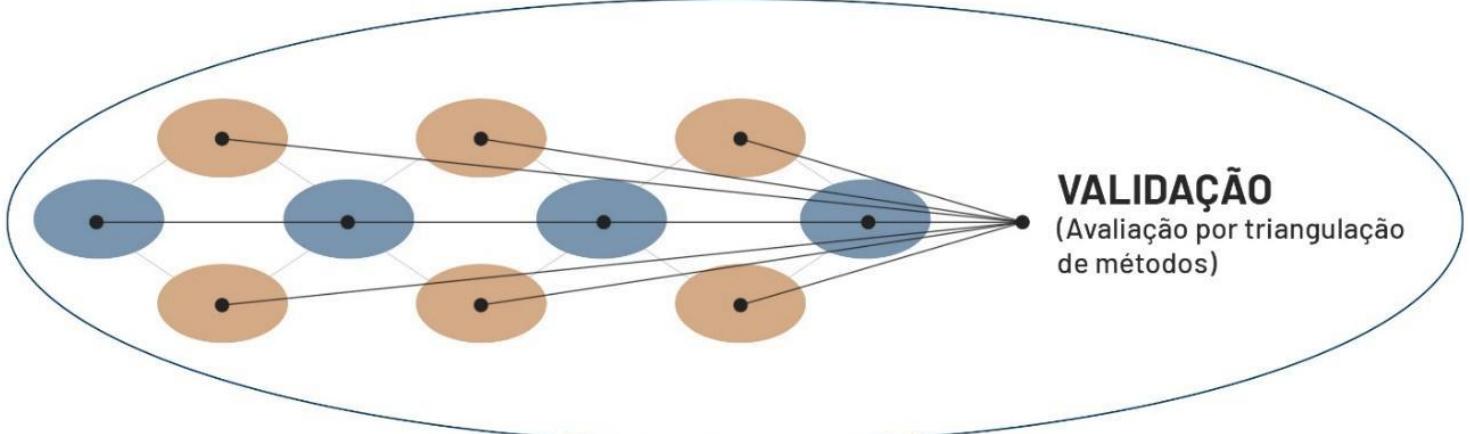

Figura 2 - Validação dos processos metodológicos.

Fonte: Elaborado pelos autores (2021) 


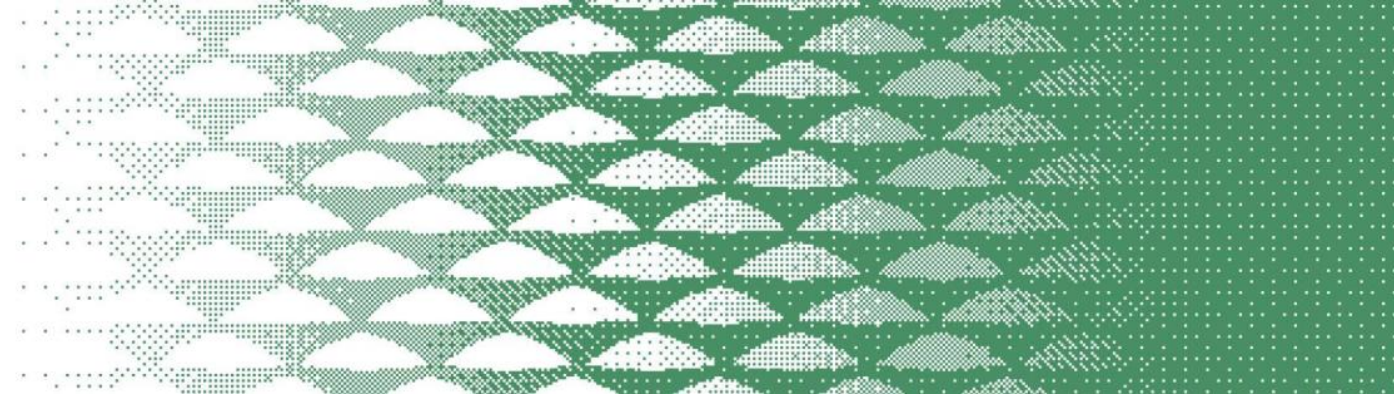

O objetivo da validação é colocar em contraponto os resultados colhidos ao final de cada etapa da metodologia, a fim de compará-las e gerar uma conclusão que traga confiabilidade para a pesquisa. A técnica utilizada será a de avaliação por triangulação de métodos.

Flick (2004) define que a triangulação põe em perspectiva a observação do pesquisador por pelo menos dois pontos de vista e que esta técnica contribui com estratégias de validação de pesquisa. Para Minayo, Assis e Souza (2005), a triangulação emerge do interacionismo simbólico e faz o cruzamento de múltiplos pontos de vista. Esta técnica é utilizada quando se constata que a análise de cada método isolado, dentro de um roteiro de pesquisa, não confere respostas suficientes para determinada investigação.

No horizonte da pesquisa, de acordo com o plano, surgem três objetos de interesse que podem ser postos em contraponto: a base de informações colhidas na fundamentação teórica, as elucidações constatadas na observação em sala de aula e as noções colhidas nas práticas experimentais, envolvendo sondagem e laboratório. A análise resultante dos três pontos de vista da pesquisa oferece a oportunidade de levantar respostas para as investigações propostas, e encaminha o estudo para uma síntese final.

\section{Considerações Finais}

O desenvolvimento da metodologia de uma dissertação de mestrado é uma tarefa complexa para atender a problemáticas também complexas. Porém a definição de caminhos se dá por meio do estudo de métodos, técnicas e ferramentas da área que engloba o referente escopo. A pesquisa experimental em design e a reivindicação do experimento como processo de design se desdobram na condução de etapas que se complementem e que possam chegar a um denominador comum.

A revisão de literatura sobre o tema apresentou estes caminhos com os conceitos das sondas e das experimentações sob as regras do laboratório de design. Dentro destes próprios métodos de pesquisa foi possível encontrar pistas que sugeriam outras etapas complementares, como a necessidade de se estruturar uma base teórica, de observar e se aproximar do sujeito de pesquisa e de sintetizar tudo ao final da pesquisa por meio da validação.

Agrupar e ordenar esses passos em forma de um plano de pesquisa em design confere uma nitidez ao processo. Se pode observar como o todo é constituído e como o fechamento de cada etapa é imprescindível para a abertura das etapas seguintes. Toda essa estruturação define um processo coerente, e espera-se que a conclusão de cada etapa traga resoluções positivas.

Que a fundamentação teórica possa estabelecer uma base de processos pedagógicos condizentes com a situação atual do ensino remoto, e, por consequência, aplicáveis ao mesmo. Que a observação possa contribuir com a compreensão das relações entre docente e discentes e com a participação efetiva nesse meio.

Que a sondagem possa traduzir a virtualidade do ensino em materialidade e que as estratégias de ensino também sejam elaboradas por estudantes. Que o laboratório possa confirmar que esse ensino menos hierarquizado e que valorize a vivência de quem estuda seja legítimo para quem aprende.

E por fim, que a validação possa tecer as conexões necessárias entre estes métodos, fazendo irromper novos processos educativos integradores que, em tempos tão difíceis, contribuam para que o distanciamento social não se converta também um distanciamento educacional. 
The design experiment in online education: the experimental research program as a method.

\section{Abstract:}

This paper presents a methodological proposal to compose a master's degree thesis in design focused on education, teaching and learning, based on the concept of program, arising from experimental studies in design and design research, aiming at the use of experimental techniques to conduct an applied and qualitative research, seeking the very own practice of design as a method.

This program preview was made with studies that deal with the conception of design experiments involving user participation through artifacts, such as design probes, and also the definition of an experimentation space, the design lab. This review aims to expose this aggregated knowledge on the subject and, finally, to design a viable research plan comprising the construction of methodologies.

\section{Keywords:}

Experimentation; methodology; design research; teaching; learning.

\section{Referências bibliográficas}

ANDER-EGG, E. Introduccion a las técnicas de investigacion social, 8.ed. Buenos Aires: Hvmanitas, 1979. $336 \mathrm{p}$.

BALAAM, M. Using technology probes to understand educational design spaces. In: LUCKIN, R.; PUNTAMBEKAT, S.; GOODYEAR, P.; GRABOWSKI, B. L.; UNDERWOOD, J.; WINTERS, N. (Orgs.). Handbook of Design in Educational Technology. London: Routledge, 2013. 71-79 p.

BANG, A. L.; ERIKSEN, M. A. Experiments all the way in programmatic design research. In: Artifact, v.3, n.2, p.4.1-4.14, 2014.

BINDER, T. BRANDT, E. The Design:Lab as platform in participatory design research. In: CoDesign, v.4, n.2, p.115-129, jun. 2008.

BINDER, T.; BRANDT, E.; HALSE, J.; FOVERSKOV. M.; OLANDER, S.; YNDIGEGN, S. Living the (codesign) lab. In: Nordic Design Research Conference, Helsinki, 2011, p.1-10.

BINDER, T.; RESDTRÖM, J. Exemplary design research. In: Design Research Society, Lisbon, p.113,2006

BRANDT, E. BINDER, T. Experimental design research: genealogy, intervention, argument. In: International Association of Societies of Design Research, Hong Kong, v.10, 2007. 17 p.

BUCHANAN, R. Design research and the new learning. In: Design Issues, v.17, n.4, p.3-23. 2001. 
DEWEY, J. Experiência e educação. Tradução: Anísio Teixeira. 2.ed. São Paulo, Ed. Nacional, 1976. $101 \mathrm{p}$.

FLICK, U. Triangulation in Qualitative Research. In: FLICK, U.; VON KARDOFF, E.; STEINKE, I. (Ed.). A companion to qualitative research. Sage, 2004. p.178-183.

FREIRE, P. Pedagogia da autonomia: saberes necessários à prática educativa. 63.ed. Rio de Janeiro/São Paulo: Paz e Terra, 2020. 143 p.

GAVER, B.; DUNNE, T.; PACENTI, E. Design: Cultural probes. In: Interactions, v.6, n.1, p.21-29, 1999.

HALSE, J.; BRANDT, E.; CLARK, B.; BINDER, T. Rehearsing the future. The Danish Design School Press: Copenhagen, 2010, 211p.

INGOLD, T. Antropologia e/como educação. Tradução: Vitor Emanuel Santos Lima, Leonardo Rangel dos Reis. Petrópolis: Vozes, 2020, 124 p.

LAKATOS, E. M.; MARCONI, M. A. Fundamentos de Metodologia Científica. São Paulo: Atlas, 2003. $311 \mathrm{p}$.

MATTELMÄKI, T. Design Probes. Tese (Doutorado em design) - University of Art and Design Helsinki, Publication series A 69. Finlândia, 2006. 220 p.

MINAYO, M.; ASSIS, S.; SOUZA, E. orgs. Avaliação por triangulação de métodos: abordagem de programas sociais. Salvador: EDUFBA; Rio de Janeiro: Editora FIOCRUZ, 2005, 244 p.

PIMENTEL, M.; CARVALHO, F. S. P. Princípios da Educação Online: para sua aula não ficar massiva nem maçante! SBC Horizontes, maio 2020. ISSN 2175-9235. Disponível em: <http://horizontes.sbc.org.br/index.php/2020/05/23/principios-educacao-online>. Acesso em: 23 março. 2021.

SANTOS, A. Seleção do método de pesquisa: guia para pós-graduando em design e áreas afins. Curitiba: Insight, 2018. 230 p.

SILVA, E.; MENEZES, E. Metodologia da pesquisa e elaboração de dissertação. 3. ed. Florianópolis: Laboratório de Ensino a Distância da UFSC, 2001. 121 p. 